\title{
Wire + Arc Additive Manufacture of 17-4 PH stainless steel: effect of different processing conditions on microstructure, hardness, and tensile strength.
}

\section{Armando Caballero*, Jialuo Ding, Supriyo Ganguly, Stewart Williams.}

Welding Engineering and Laser Processing Centre, Cranfield University, Cranfield MK43 OAL, UK.

\begin{abstract}
Wire + Arc Additive Manufacture (WAAM) is receiving increasing attention as it offers a way to fabricate meter scale parts, with low capital cost and material waste. A wide range of metallic alloys are suitable for this process. Martensitic grade precipitation-hardening stainless steel 17-4 PH offers a good compromise between high strength and corrosion resistance. Hence, it is important to investigate the behaviour of this alloy in WAAM. In the present work, the effect of different process variables such as shielding gas, deposition path and post-fabrication heat treatment, on microstructure and mechanical properties was studied. A series of samples were manufactured by WAAM using the Fronius Cold Metal Transfer (CMT) process under different conditions and they were subsequently characterized by optical and electron microscopy and mechanical properties in terms of strength and hardness. It was found that using shielding gases that result in higher heat input reduces the amount of retained austenite in the asdeposited microstructure. Additionally, it was demonstrated that required tensile properties can be achieved by adequate post-processing heat treatment. However, it is suggested that direct aging in as deposited condition resulted in formation of harmful interdendritic phases which embrittles the deposit.
\end{abstract}

Keywords: Additive Manufacture, WAAM, Retained Austenite, 17-4 PH.

${ }^{*}$ corresponding author.

E-mail address: a.e.caballeroramos@cranfield.ac.uk 


\section{Introduction}

Additive manufacturing (AM) has several advantages as compared to traditional manufacturing processes, including the potential reduction of costs and lead times and the possibility to create almost any shape (Wong and Hernandez, 2012). Depending on the material feedstock AM systems can be classified as powder bed, powder feed or wire feed systems (Frazier, 2014). The latter has experienced increasing interest through the wire + arc additive manufacture (WAAM) process. Where an electric arc is used as the heat source, in combination with metallic wire as feedstock, in order to fabricate near net shape components by the consolidation of several consecutive layers. Its main benefits include the capability of building medium to large scale components at relatively high deposition rates, reduction in material waste and low capital and feedstock costs. Ti-6Al-4V, aluminium, steel, copper, and nickel alloys have been successfully deposited by WAAM (Williams et al., 2015). Martensitic stainless steel 17-4 PH is a good candidate for WAAM as it could provide a good combination of strength and corrosion resistance which are ideal for severe service conditions. Additionally, it provides the possibility of tailoring required mechanical properties through careful heat treatment. High strength in this material is obtained by the precipitation of dispersed submicroscopic Cu-rich particles inside the martensitic matrix during ageing (Bressan et al., 2008).

In the field of 17-4 PH stainless steel AM, most of the existing reported work has been on laser + powder processing, where 3D components are manufactured the layer-by-layer melting of a pre-placed metallic powder bed using a laser beam. Current research programmes focus on the improvements and optimization of these powder-based processes. Matilainen et al. (2014) studied the process efficiency as a function of laser power and layer thickness. While Järvinen et al. (2014) have studied the implementation of different designs of support structures to improve the end quality of the part. On the other hand, other works have focused on the microstructure and mechanical properties of selective laser melting (SLM) of 17-4 PH stainless steel. LeBrun et al. (2015) investigated the influence of thermal processing after SLM and its effect on retained austenite and mechanical properties. They showed that a solution heat treatment is necessary after fabrication in order to achieve satisfactory properties after ageing, mainly due to high percentages of retained austenite in the as-fabricated condition. Moreover, they determined an increase in work hardening rates during tensile testing of as-fabricated specimens as consequence of the stress-induced transformation of the retained austenite to martensite. Facchini et al. (2010) found similar results where 17-4 PH samples produced by SLM exhibited exceptional work hardening as consequence of the same solid state 
transformation. However, in contrast to LeBrun et al.(2015), they were not able to achieve required tensile properties after thermal processing of additively built 17-4 $\mathrm{PH}$. This is probably due to the fact that Facchini et al. (2010) identified $72 \%$ of retained austenite as compared to $36 \%$ found by LeBrun et al.(2015). Aging response of austenite is not satisfactory due to its higher solubility for Cu-precipitates (Hsiao et al., 2002). Therefore, strengthening by the ageing of this alloy is limited to higher percentages of retained austenite. The unusually high volume percentages of this metastable phase reported in the aforementioned literature are seen to be a consequence of mechanical stabilization due to thermomechanical residual stresses accumulated during the repetitive solidification and cooling down cycles experienced by the samples during SLM processing. Despite the tensile test analysis carried out by the previously mentioned works, none of them has considered the comparison of tensile properties both in parallel and perpendicular direction, with respect to the building direction. Nevertheless, additional mechanical properties characterization has been performed on selective laser melted 17-4 PH.

Comprehensive hardness maps were presented by Rashid et al. (2017) for two different SLM scan strategies, single and double melting of each layer. It was found that the hardness values for the double melted samples were higher as less percentage of retained austenite was found for this condition, $485 \mathrm{HV}$, and 14\% respectively. Conversely, single melted layer samples showed 365 HV with 33\% of retained austenite. Cheruvathur et al. (2015) also reported hardness values ranging from $258 \mathrm{HV}$, in the as-fabricated condition, up to $318 \mathrm{HV}$ after solutionizing heat treatment. LeBrun et al. (2015) measured $333 \mathrm{HV}$ and $330 \mathrm{HV}$ for the as fabricated and solution treated condition correspondingly. We can suggest that the differences in hardness values described by various authors are related to the use of a wide range of different SLM process parameters during fabrication, such as scanning speed, powder layer thickness, laser power, laser spot size and hatch distance. Each specific combination of these variables will produce unique cooling rates and thermal cycles that can create very dissimilar microstructural features. Yadollahi et al. (2016) went a step further with the mechanical characterization of SLM 17-4 PH and tested the effect of building orientation and postfabrication heat treatment on fatigue behavior. Finding a higher fatigue strength of horizontally built specimens due to the orientation of deposited layers and defects with respect to the loading axis. As we have described in this section, several mechanical characterizations have being performed on SLM 17-4 PH samples, proving that the percentages of retained austenite can have an important effect on final mechanical properties and heat treatment response. Hence, investigation of this retained phase and its quantification have been one of the main focus of previous research. Regardless of the efforts done to characterize additively manufactured 17-4 PH components, all current research focuses only on SLM. No previous 
characterization of an alternative AM process such as WAAAM has been considered. In this paper, we describe the effect of different processing conditions, of WAAM manufactured 17-4 $\mathrm{PH}$, on microstructure, hardness, and tensile strength.

\section{Experimental procedure}

Samples in this work were deposited using Fronius cold metal transfer (CMT) process, using a travel speed of $6.2 \mathrm{~mm} / \mathrm{sec}$ and a wire feed speed of $6 \mathrm{~m} / \mathrm{min}$. Commercial 17-4 PH welding wire of $1.2 \mathrm{~mm}$ was used. Table 1 shows the chemical composition. Samples were deposited over 12 mm thick 304 austenitic stainless steel substrate.

Table 1. Chemical composition of 17-4 PH welding wire used.

\begin{tabular}{|l|l|l|l|l|l|l|l|l|l|l|l|}
\hline Element & $\mathrm{C}$ & $\mathrm{Cr}$ & $\mathrm{Cu}$ & $\mathrm{Mn}$ & $\mathrm{Mo}$ & $\mathrm{Nb}$ & $\mathrm{Ni}$ & $\mathrm{P}$ & $\mathrm{S}$ & $\mathrm{Si}$ & $\mathrm{Fe}$ \\
\hline Percentage (\%) & 0.024 & 16.44 & 3.53 & 0.56 & 0.220 & 0.15 & 4.74 & 0.020 & 0.005 & 0.50 & bal \\
\hline
\end{tabular}

Three different deposition strategies were investigated in the presented work: single, oscillated and parallel pass (Fig. 1). For a single pass, each layer is formed by a single bead of deposited molten metal. In the oscillated path, the torch moves with a specific oscillation width to form wider layers. Parallel pass consists of a sequence of single beads deposited next to each other in order to form each layer, wider widths can also be achieved with this strategy. Different deposition strategies are experimented with as they will induce different thermal cycles in the deposited metal due to dissimilar thermal masses and heat accumulation.

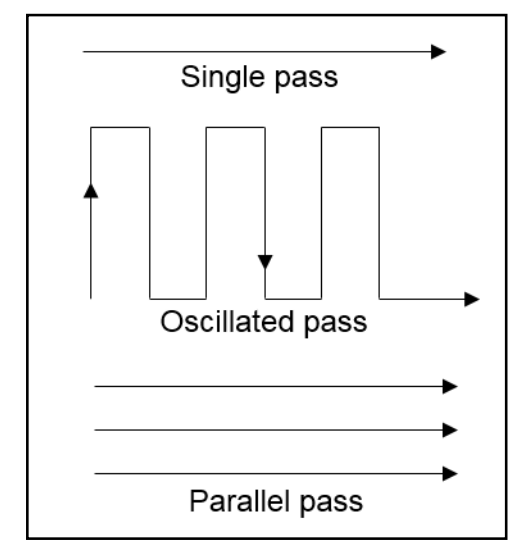

Fig. 1. Different deposition strategies used in this work. 


\subsection{Shielding gas assessment}

Two different tailored shielding gases were experimented during deposition of two single pass samples. In this text, it is referred as shielding gas 1 (SG1) and shielding gas 2 (SG2). SG1 was made of $38 \% \mathrm{He}$ and $2 \% \mathrm{CO}_{2}$ in argon. While SG2 was made of $2.5 \% \mathrm{CO}_{2}$ in argon. Samples were deposited inside a small argon filled environmental chamber. This allowed the study of the direct effect of the shielding gas on the microstructure of the deposited samples. Samples were $6 \mathrm{~mm} \times 19 \mathrm{~mm} \times 190 \mathrm{~mm}$ long and formed by 10 layers. The experimental set up is shown in Fig. 2.

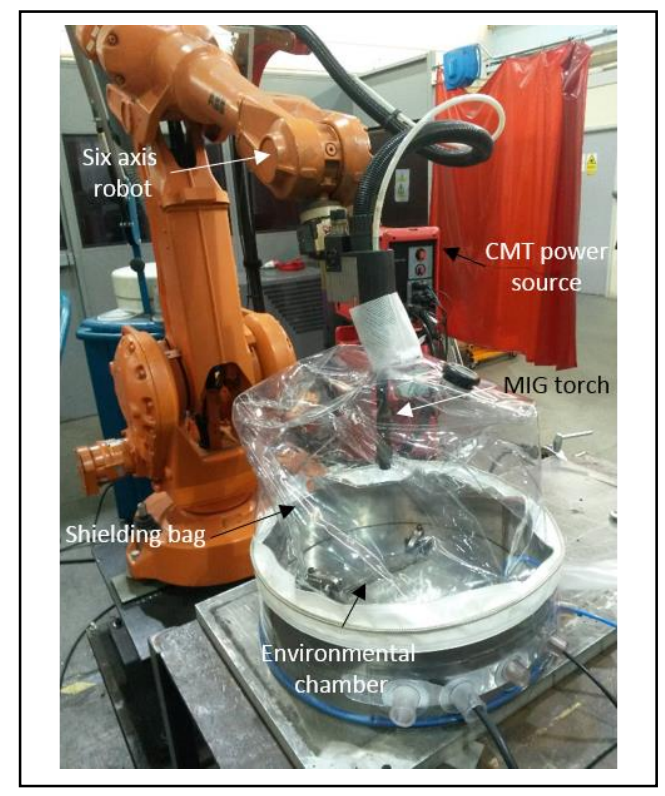

Fig. 2. Experimental set up for the shielding gas assessment.

Electron backscatter diffraction (EBSD) was performed for these two samples with the purpose of phase identification and phase fraction distribution. The EBSD scan was focused on the middle region of each sample cross-section and three different fields were analyzed for each sample.

\subsection{Effect of different heat treatments conditions on different shielding gas and deposition strategies.}

A series of heat treatments were performed on the samples deposited using different deposition strategies. Oscillated and parallel deposition strategies were used to manufacture a total of four specimens. Two, using oscillated pass, and other two using parallel pass. Within each deposition strategy, the two previously described shielding gases (SG1 and SG2) were used to build each sample. Subsequently, $8 \mathrm{~mm}$ thick cross-sections perpendicular to the building direction were taken from each sample in order to apply the different heat treatments. Samples underwent standardized solution treatment (1040 ํㅡ for 30 minutes) and H900 
ageing treatment (480 ${ }^{\circ} \mathrm{C}$ for $1 \mathrm{~h}$ ), an electric air furnace was used for this purpose. Four different conditions were used for post-fabrication heat treatment: as deposited (AD), as deposited plus solution treatment $(A D+S T)$, as deposited plus H900 ageing treatment $(\mathrm{AD}+\mathrm{H} 900)$ and as deposited followed by solution treatment and $\mathrm{H} 900$ ageing (ST+H900). Table 2 summarizes the different conditions and heat treatments done in this section. The aim of performing direct ageing on $A D$ condition was to assess if required properties could be achieved without completing the ST step. Hardness measurements were performed as a function of the number of deposited layers (sample height).

Table 2. Experimental matrix of the different heat treatments performed.

\begin{tabular}{|c|c|c|}
\hline $\begin{array}{c}\text { Deposition } \\
\text { Strategy }\end{array}$ & $\begin{array}{c}\text { Shielding } \\
\text { Gas }\end{array}$ & $\begin{array}{c}\text { Heat } \\
\text { treatment }\end{array}$ \\
\hline \multirow{8}{*}{ Oscillated pass } & \multirow{4}{*}{ SG1 } & $A D$ \\
\hline & & ST \\
\hline & & $\mathrm{AD}+\mathrm{H} 900$ \\
\hline & & $\mathrm{ST}+\mathrm{H} 900$ \\
\hline & \multirow{4}{*}{ SG2 } & $A D$ \\
\hline & & ST \\
\hline & & $\mathrm{AD}+\mathrm{H} 900$ \\
\hline & & $\mathrm{ST}+\mathrm{H} 900$ \\
\hline \multirow{8}{*}{ Parallel pass } & \multirow{4}{*}{ SG1 } & $A D$ \\
\hline & & ST \\
\hline & & $\mathrm{AD}+\mathrm{H} 900$ \\
\hline & & $\mathrm{ST}+\mathrm{H} 900$ \\
\hline & \multirow{4}{*}{ SG2 } & $A D$ \\
\hline & & ST \\
\hline & & $\mathrm{AD}+\mathrm{H} 900$ \\
\hline & & $\mathrm{ST}+\mathrm{H} 900$ \\
\hline
\end{tabular}

\subsection{Effect of H900 ageing on tensile properties.}

To assess the effect of heat treatment on tensile properties only one shielding gas was used and only the single pass deposition strategy was considered. One single pass wall was built for this purpose using SG1. The same four different conditions described in the previous section were used for tensile testing; $A D, A D+S T, A D+H 900$ and $S T+H 900$. Every condition was tested in both vertical and horizontal direction with respect the deposition direction. Three coupons per condition were tested and they were machined from within the bulk of the samples. Coupons dimensions were selected following the BS EN 2002-1: 2005 and are indicated in Fig. 3. Tensile testing was carried out using an electromechanical Instron 5500R frame with a load cell of $100 \mathrm{KN}$ and a strain rate of $0.2 \mathrm{~mm} / \mathrm{min}$. For the purpose of this study, mechanical properties stated in ASTM A564/A564M-02a standard were used as reference. 
Fractographic analysis was also carried out using a Philips XL-30 SFEG scanning electron microscope (SEM).

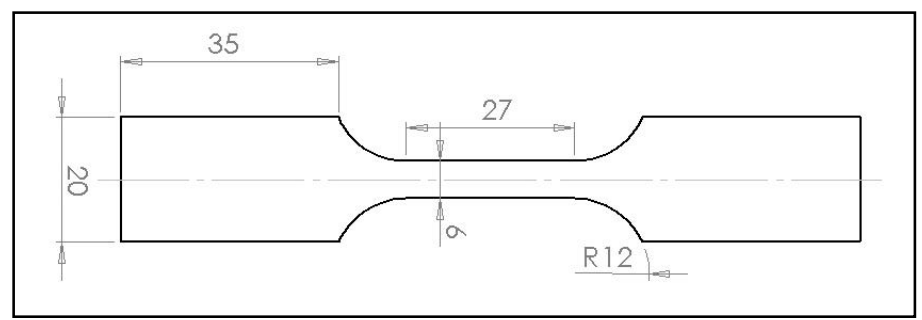

Fig. 3. Geometry of the uniaxial tensile specimens, thickness $4 \mathrm{~mm}$ (unit: $\mathrm{mm}$ ).

\subsection{Samples processing.}

For metallographic characterization, samples were ground using abrasive papers with grit from 120 to 2500 and polished using $6 \mu \mathrm{m}$ and $3 \mu \mathrm{m}$ diamond suspension, followed by final polishing with $0.5 \mu \mathrm{m}$ colloidal silica. Kalling's 2 etchant (cupric chloride, hydrochloric acid and ethanol) was used to reveal the microstructure. Additionally, Vickers hardness measurements were performed according to BS EN ISO 6507-1 using a load of $30 \mathrm{Kgs}$. 


\section{Results}

2.1. Microstructure examined by Optical Microscopy (OM) and EBSD.

Micrographs of WAAM samples in the AD condition and after ST plus H900 ageing are shown in Fig. 4. The AD condition is characterized by a dendritic microstructure with the presence of interdendritic $\delta$-ferrite in a martensitic matrix (Fig. 4a). A lower magnification field of a crosssection, perpendicular to the deposition direction, taken from the sample manufactured for tensile testing (Fig. $\mathbf{4 b}$ ), reveal a columnar microstructure orientated perpendicular to the building direction. In the ST and aged condition, the microstructure is mainly formed by tempered Martensite; $\delta$-ferrite or the columnar features are no longer seen (Fig. 4c).

Fig. 4. Microstructure: (a) as-deposited condition of sample manufactured with SG1: (b) sample used for tensile testing, AD + H900 condition; (c) sample used for tensile testing, ST+H900 condition.

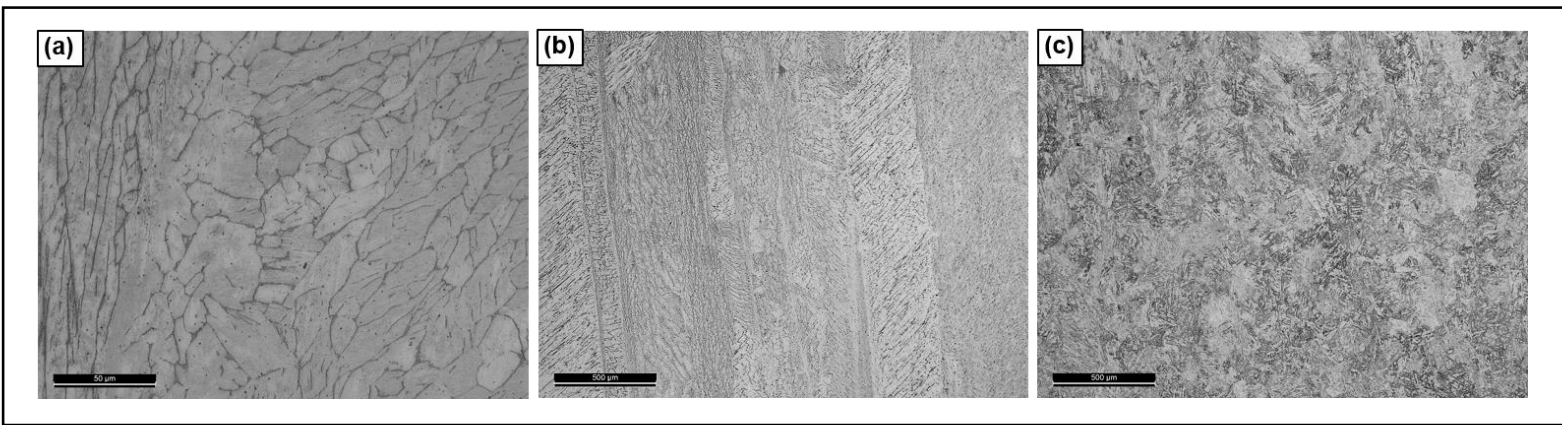


Fig.5 illustrates the EBSD phase mapping results for samples manufactured using two different shielding gases (section 2.1). For the sample built using SG2, a higher percentage of retained austenite was measured $(0.85 \%$, area percentage) as compared to sample built using SG1 (0.12\%, area percentage). Images were processed to highlight the retained austenite (black/white contrast images on the right).

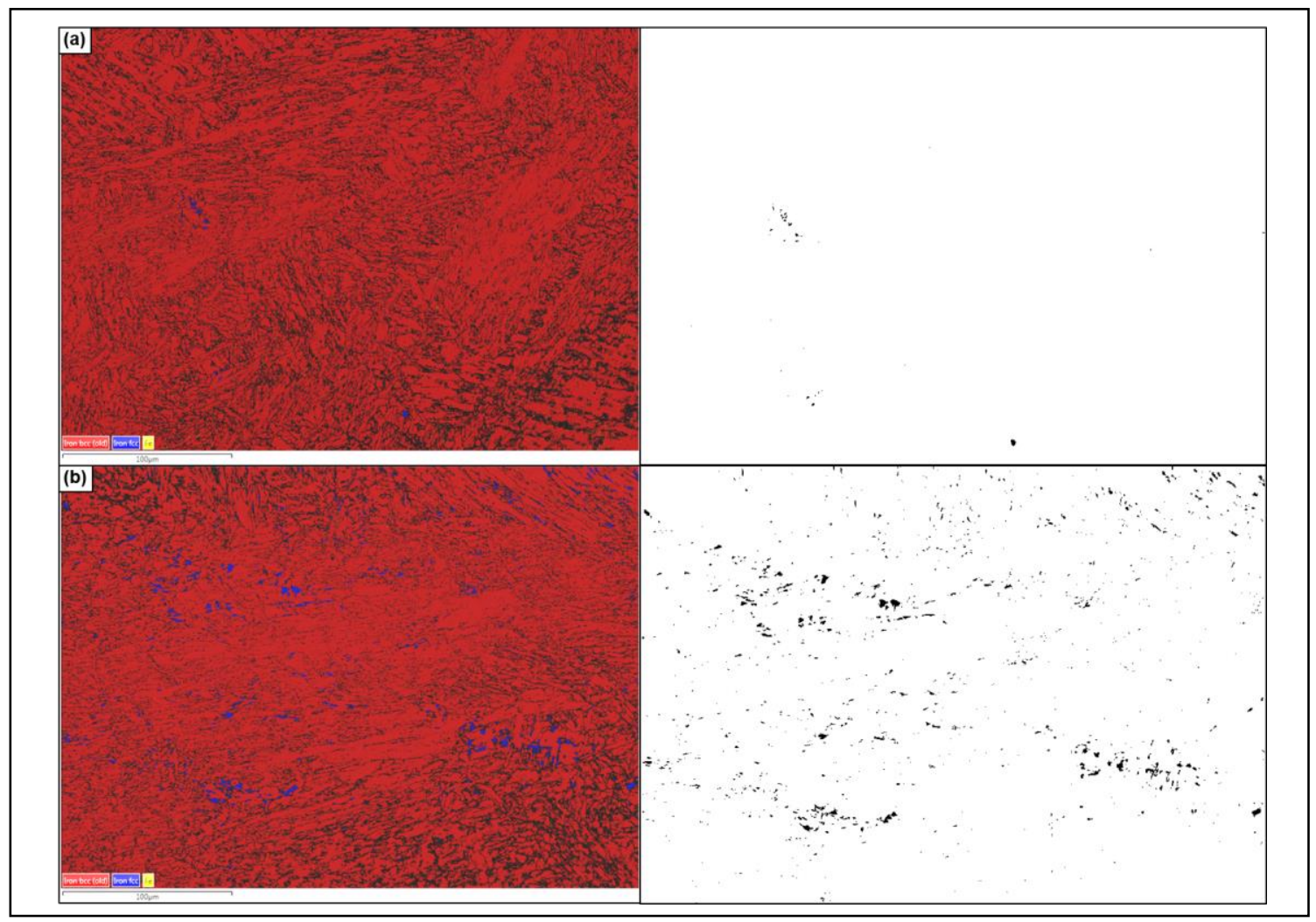

Fig. 5. EBSD phase mapping for samples manufacture with SG1 a; and SG2 b. BCC/Martensite, FCC/Austenite.

2.2. Effect of different heat treatments conditions on different shielding gas and deposition strategies.

Vickers hardness as a function of the sample height for each deposition strategy is presented in Fig. 6. For the deposit produced by oscillation of the tool path (Fig. 6a), it can be observed that the highest hardness corresponds to $\mathrm{H} 900$ ageing. The minimum and maximum values obtained for this treatment are 408 and 448 HV30 respectively. According to ASTM A564, minimum hardness value has to be $396 \mathrm{HV}$ for condition H900. Hence, both AD+H900 and $\mathrm{ST}+\mathrm{H} 900$ comply with the hardness requirements. Solution treated samples without any further ageing show lower hardness in comparison with the AD state. Parallel deposition strategy samples (Fig. 6b) also comply with the required hardness values and the same 
behaviour previously described can be observed. For both strategies, hardness does not change significantly as a function of the height (number of deposited layers).

The difference in hardness values by changing shielding gas is more significant for the oscillated strategy as compared to the parallel, particularly for H900 treatment. After solution treatment, the changes in hardness by using difference gases is minor. In the case of the parallel deposition, solution treating produces higher hardness for SG2 as compared to SG1.

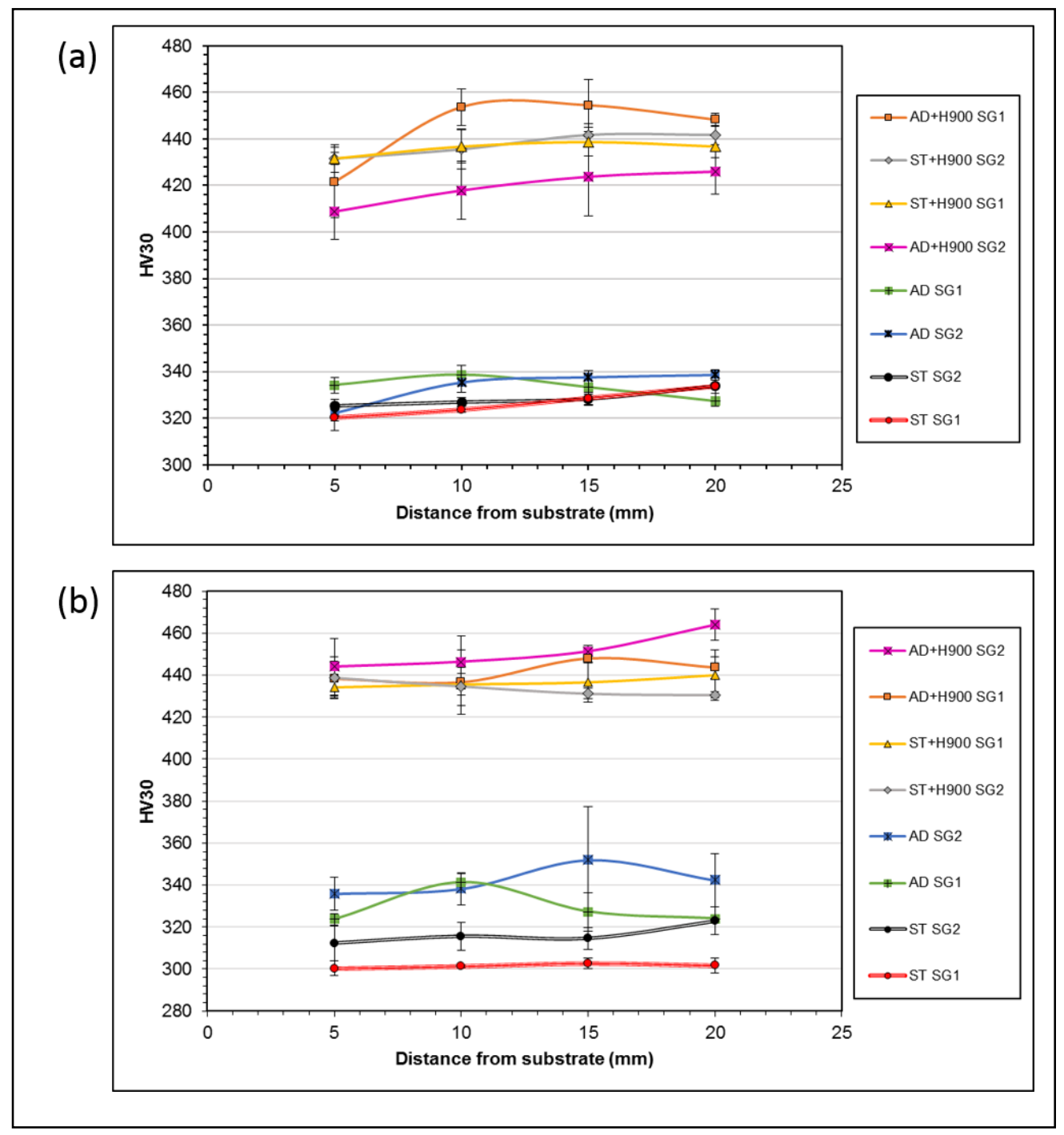

Fig. 6. Hardness as a function of sample height (number of deposited layers). (a) Oscillated pass deposition strategy; (b) Parallel pass deposition strategy.

A hardness comparison between both deposition strategies with ageing treatment applied without prior solution treatment is plotted together in Fig. 7a. For AD+H900 SG1 hardness values are not significantly different between oscillated and parallel passes; especially for 
distances of 15 and $20 \mathrm{~mm}$ from the substrate. There is a more significant gap amongst deposition strategies for the same $A D+H 900$ condition built with SG2. A maximum value of $426 \mathrm{HV} 30$ is observed for the oscillated pass, while $464 \mathrm{HV} 30$ is measured as the maximum for the parallel strategy. Fig. 7b shows the hardness values after ST and subsequent ageing; it is evident from the plot that, for all combination of deposition strategies and shielding gases, hardness does not change in any significant way for each ageing treatment. This is, applying ST before ageing produces similar values of hardness for all the different process condition used, being dependent only on the subsequent ageing applied.

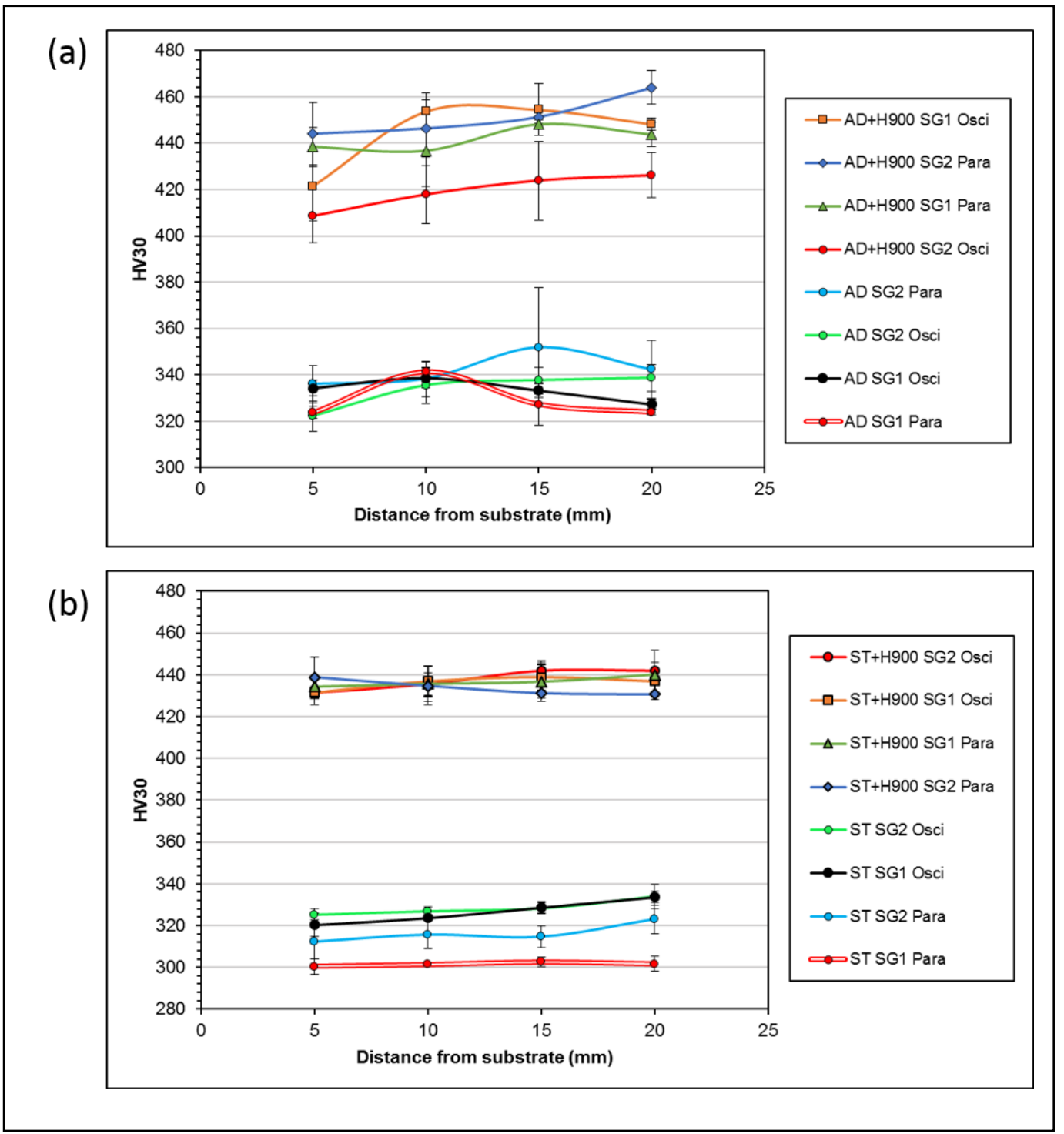

Fig. 7. Hardness as a function of sample height. (a) Comparison between oscillated and parallel strategy with and without ageing in AD condition; (b) Comparison between oscillated and parallel strategy in ST condition with and without ageing treatment.

\subsection{Effect of H900 ageing on tensile properties.}


Table 3 summarizes the results obtained from tensile testing. Only the samples with solution treatment and $\mathrm{H} 900$ ageing comply with the requirements of the ASTM A 564/A 564M-02a standard for $\mathrm{H} 900$ age hardened 17-4 PH, PS at $1170 \mathrm{MPa}$, UTS at $1310 \mathrm{MPa}$ and elongation at $10 \%$. These samples give the highest PS at $1229 \mathrm{MPa}$, the highest UTS at $1352 \mathrm{MPa}$ and the highest elongation of $13.8 \%$. Solution treating the AD samples, without ageing, only gives a marginal increase of less than $1 \%$ in tensile properties. Direct $\mathrm{H} 900$ ageing of the AD condition produces an increase in PS and UTS as compare to AD and AD+ST samples, however, elongation percentage decreased significantly from $12 \%$ to $7 \%$.

Table 3. Tensile properties results for different thermal processing conditions. Average and directionspecific results.

\begin{tabular}{|c|c|c|c|c|c|c|c|}
\hline Condition & $\begin{array}{l}\text { Sample } \\
\text { direction }\end{array}$ & $\begin{array}{c}\mathrm{PS} \\
(\mathrm{MPa})\end{array}$ & $\begin{array}{l}\text { Std } \\
\text { dev }\end{array}$ & $\begin{array}{c}\text { UTS } \\
(\mathrm{MPa})\end{array}$ & $\begin{array}{l}\text { Std } \\
\text { dev }\end{array}$ & Elongation \% & $\begin{array}{l}\text { Std } \\
\text { dev }\end{array}$ \\
\hline \multirow{3}{*}{$A D$} & Average & 790 & 73 & 994 & 39 & 11.9 & 0.6 \\
\hline & Vertical & 738 & 30 & 979 & 13 & 12.2 & 0.7 \\
\hline & Horizontal & 842 & 65 & 1009 & 55 & 11.6 & 0.3 \\
\hline \multirow{3}{*}{$A D+S T$} & Average & 821 & 17 & 1003 & 6 & 12.6 & 0.4 \\
\hline & Vertical & 827 & 4 & 1006 & 6 & 12.4 & 0.4 \\
\hline & Horizontal & 815 & 24 & 1000 & 5 & 12.8 & 0.2 \\
\hline \multirow{3}{*}{$\mathrm{AD}+\mathrm{H} 900$} & Average & 1099 & 57 & 1208 & 95 & 7.3 & 1.2 \\
\hline & Vertical & 1059 & 9 & 1124 & 5 & 6.5 & 0.3 \\
\hline & Horizontal & 1140 & 57 & 1293 & 32 & 8.2 & 1.3 \\
\hline \multirow{3}{*}{$\mathrm{ST}+\mathrm{H} 900$} & Average & 1229 & 31 & 1352 & 8 & 13.8 & 0.9 \\
\hline & Vertical & 1234 & 33 & 1351 & 11 & 13.8 & 0.5 \\
\hline & Horizontal & 1225 & 36 & 1353 & 6 & 13.8 & 1.4 \\
\hline
\end{tabular}

Within each condition, it does not seem to be a significant difference between properties and orientation. In order to assess this, the p-values of the t-student test were calculated. Anisotropy was only observed ( $p$-value $<0.05$ ) in the case of the UTS values for the AD + H900 condition.

Fracture morphologies obtained by SEM of vertically orientated tensile coupons, with respect to the deposition direction, are shown in Fig. 8a. Tension-induced fracture morphology was dominated by round dimples in the case of the ST + H900 condition. For AD + H900 condition, 
dimples are identified, together with some localized regions where flat facets are observed, suggesting a localized brittle behaviour (Fig. $\mathbf{8 b}$ and c).

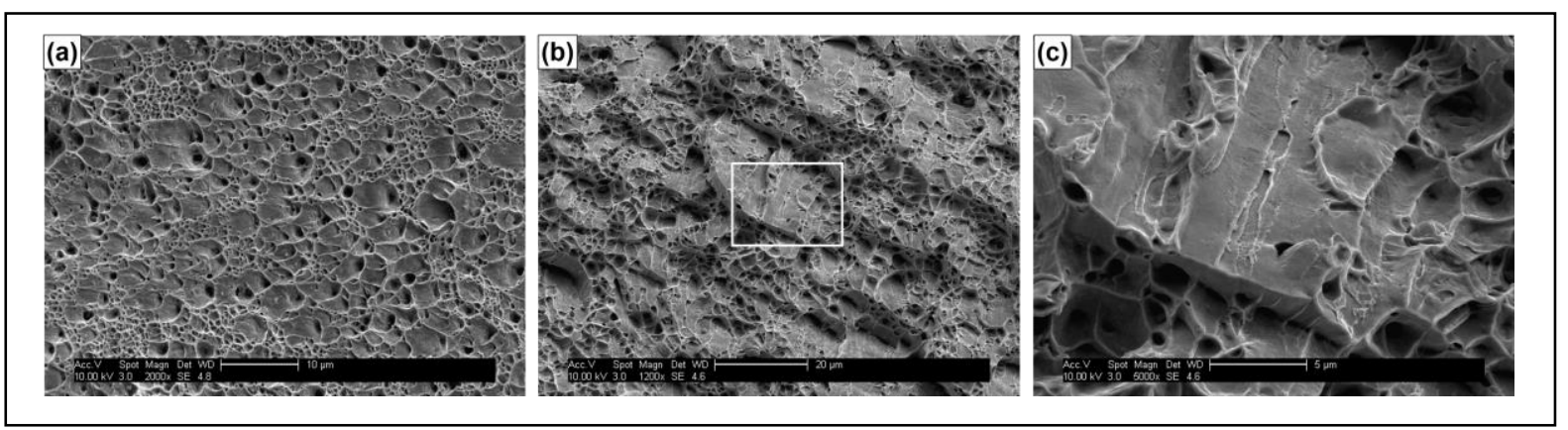

Fig. 8. SEM images showing the fractographs of tensile fracture surfaces of condition: (a) ST + H900:

(b) AD+H900: (c) Magnification of b. 


\section{Discussion}

Alloy 17-4 $\mathrm{PH}$ has a $\mathrm{Cr}_{\text {eq }} / \mathrm{Ni}_{\text {eq }}$ ratio greater than 1.55 , which produces a primary ferritic solidification mode. Under equilibrium cooling, the following phase transformation sequence takes place: $L \rightarrow \delta$-ferrite $\rightarrow y$-austenite $+\delta$-ferrite $\rightarrow$ martensite $+\delta$-ferrite (Ziewiec and Tasak, 2014). However, cooling rates inherent to WAAM deposition, limit the amount of $\delta$ ferrite that can transform to $\gamma$-austenite. Hence, some fraction of $\delta$-ferrite will remain at room temperature (Fig. 4a). The same behaviour has been observed before for welding of 17-4 PH (Das et al., 2006). This results in the formation of a dendritic martensite- $\delta$ ferrite microstructure for all the $A D$ condition samples analysed in this work. Compositional heterogeneities and microsegregation are expected between dendritic and interdendritic regions, as well as partitioning of solute elements as consequence of solubility differences between phases. After ST, microstructure changes to nearly $100 \%$ lath martensite (Fig. 4c). The exposure at temperatures above $\mathrm{Ac}_{3}$ and the slower cooling rate of the air cooling promote the transformation of most of the $\delta$-ferrite into austenite that can then transforms to martensite. During soaking, sufficient time is given for diffusion to occur and it is expected that dendritic segregation is removed, together with the dissolution of precipitates. Therefore, microstructure under this condition should show more homogenous properties in terms of hardness and tensile strength. This point will be explained further in the analysis of hardness and tensile test results.

EBSD for phase identification reveals lower percentages of retained austenite for the samples built using SG1 (Fig. 5). A higher heat input and therefore a slower cooling rate is expected when using SG1, due to the presence of He on this gas (Zähr et al., 2012). When the cooling rate is reduced, more time is allowed to promote the formation of austenite in the solid state, resulting in higher percentages of retained austenite at room temperature. As described in the introductory section of this work, retained austenite can be detrimental to some properties of 17-4 PH. For this reason, SG1 was selected to build the samples for tensile mechanical testing.

It is well known that coherent $\mathrm{Cu}$-rich precipitates are responsible for the increase of hardness in 17-4 PH (Das et al., 2006). Results from Fig. 6a and $\mathbf{b}$ allow us to establish that an increase of hardness can be obtained by ageing directly on AD condition without any ST. Apart from the fact that the precipitation of hardening coherent Cu-enriched particles in the martensite is promoted during ageing, it has been shown by Yoo et al. (2006) that $\delta$-ferrite can also experience an increase in hardness as a consequence of the nucleation and growth of precipitates. This could explain why in some cases, hardness values for the $\mathrm{AD}+\mathrm{H} 900$ samples are higher than the ones obtained for $\mathrm{ST}+\mathrm{H} 900$. 
Comparing both deposition strategies for the AD state (Fig. 7a), it can be seen that there is no consistent trend in the hardness values between deposition paths. In other words, for the same shielding gas, in some cases, the hardness for oscillated pass is higher and in others, parallel path shows higher values. This could be a consequence of the repetitive thermal cycles inherent to the WAAM process. As measured by Xiong et al. (2017), during WAAM of steel, every time a new layer is deposited, the temperature can increase repetitively to at least $450 \stackrel{\circ}{ } \mathrm{C}$, even if the heat source is already well away in a subsequent layer. Hence, as different regions of the build will experience different thermal cycles, some of these regions could have a different degree of ageing (underaged, aged or overaged). Therefore, hardness measurements show a fluctuating behaviour depending on the amount and size of $\mathrm{Cu}$ enriched precipitated particles. It was identified that, in all cases, ST samples show lower hardness compared to $A D$ condition. This helps to further support that during WAAM deposition some degree of particles precipitation takes place during the repetitive thermal cycling. Through ST, all the precipitates are expected to dissolve back into solid solution, creating a softer and homogeneous microstructure (error bars become smaller for ST samples as compared to AD).

From Fig. 7b it is evident how the differences in hardness are negligible after ST is applied, regardless of the deposition strategy or the shielding gas used. This is a consequence of the more homogeneous morphology obtained after solution treatment, as previously explained. Additionally, hardness profiles become almost horizontal lines, meaning that any degree of ageing that could exist in different regions of the samples, is standardized by the ST. Therefore, we propose that the final hardness of WAAM 17-4 PH manufactured components can be carefully adjusted by post-deposition thermal treatment, independent of the deposition path or shielding gas used. Tensile test results helped to further analyse the influence of different phases such as lath martensite and $\delta$-ferrite on mechanical properties.

It was only possible to achieve the required tensile properties by applying solutionizing heat treatment prior ageing. This condition guarantees a homogenous microstructure of nearly $100 \%$ lath martensite where segregated elements and precipitates have dissolved back into solid solution during ST. Additionally, upon ageing, precipitates nucleation and growth will take place evenly, producing the expected tensile behaviour (Table 2, ST + H900). This is the reason why a ST prior ageing proved to be successful in this work in order to get the required minima for tensile properties. Fracture surface morphologies are consistent with the tensile test results. The sample in ST + H900 condition showed a fracture dominated by a large number of round or equiaxed dimples (Fig. 8a), which corresponds to the ductile behaviour of a $13.8 \%$ elongation value. A more detailed analysis of Fig. 8 a shows a network of smaller 
dimples, this is probably related to the voids initiating in very fine second phase particles generated during the ageing step (Das and Tarafder, 2008).

The significant drop by nearly $50 \%$ in ductility between $\mathrm{AD}+\mathrm{H} 900$ and $\mathrm{ST}+\mathrm{H} 900$ condition can be attributed to the highly heterogeneous nature of the microstructure in the AD state. Segregation and solute partitioning will produce phases with different strength and hence, different behaviour to uniaxial tensile load. We can also suggest that a further increase of precipitates in the $\delta$-ferrite phase during ageing might reduce the ductility. Several authors have reported that $\delta$-ferrite embrittlement is possible as consequence of nucleation and growth of precipitates in this phase. The mechanism of $\delta$-ferrite embrittlement has been described only for long exposure ageing at $400 \stackrel{\circ}{ } \mathrm{C}$ (You et al., 2005); where precipitates can grow and change from rounded shape to rectangular shape which is associated with severe embrittlement. However, the repetitive thermal cycles during WAAM deposition may expose certain regions to higher temperatures that could be equivalent to prolonged $400 \stackrel{\circ}{\mathrm{C}}$ ageing. This is not the case after ST, as these particles can dissolve back into solid solution and they will only grow marginally in the subsequent ageing treatment. Additionally, volume fractions of $\delta$-ferrite tend to reduce by exposition to temperatures above $\mathrm{Ac}_{3}$ (Yoo et al., 2006). Hence, after ST, no $\delta$-ferrite phase is available for any subsequent embrittlement. Fracture morphology showed in Fig. $\mathbf{8 c}$ serves as evidence of dendritic segregation and possible localized $\delta$-ferrite embrittlement, as some regions exhibit cleavage facets characteristic of brittle behaviour in combination with ductile areas.

Direction-specific results showed some differences in terms of strength and elongation. However, the t-student test only showed a statistical significance difference only for of the UTS value of $A D+H 900$ samples (Table 3). This anisotropic response is related to the columnar microstructure observed in Fig. 4b. This characteristic has been observed before for WAAM of other materials such as Ti-6Al-4V, where columnar grains have also been identified (Wang et al., 2013). For solution treated and aged samples no anisotropy was observed as the columnar macrostructure is eliminated during thermal processing (Fig. 4c). 


\section{Conclusions}

From the different characterizations performed, the following conclusions can be drawn:

- As deposited WAAM 17-4 PH is formed of a dendritic martensite- $\delta$ ferrite microstructure, with very small percentages of retained austenite. This dendritic microstructure is expected to have compositional heterogeneities and microsegregation between dendritic and interdendritic regions. After solution treatment, microstructure transforms to nearly $100 \%$ lath martensite where segregated elements has been dissolved back into solid solution;

- Using a shielding gas with lower heat input promotes higher percentages of retained austenite in the as-deposited microstructure;

- Any hardness value required for a WAAM17-4 PH component can be achieved by applying the relevant standardized heat treatment, regardless of the deposition path or the shielding gas used during manufacturing;

- In order to achieve the required tensile properties for the H900 condition, 17-4 PH manufactured by WAAM has to go through a solution treatment and subsequent ageing. Direct ageing (no prior solution treatment) on the as-deposited condition produces a decrease in ductility of $50 \%$;

- It is suggested that the $\delta$-ferrite phase embrittlement is contributing to the ductility drop after direct ageing on the as-deposited condition. Localized brittle facets found in the fractographs corresponding to these samples serve as evidence of this mechanism;

- Anisotropy in tensile behaviour was identified only for the ultimate tensile strength of as-deposited samples with only an ageing treatment.

\section{Acknowledgments}

The authors would like to thank the WAAMMat programme for the financial support. They would also like to thank, Dr Xianwei Liu for his support on the EBSD analysis and Nisar Sha, Flemming Nielsen and Steve Pope for their technical assistance. 


\section{References}

ASTM A 564/A 564M-02a Standard Specification for Hot-Rolled and Cold-Finished AgeHardening Stainless Steel Bars and Shapes. West Conshohocken, PA: ASTM International, 2002.

Bressan, J.D., Daros, D.P., Sokolowski, A., Mesquita, R.A., Barbosa, C.A., 2008. Influence of hardness on the wear resistance of 17-4 PH stainless steel evaluated by the pin-on-disc testing. J. Mater. Process. Technol. 205, 353-359.

BS EN 2002-1:2005. Metallic materials-Test methods-Part 1: Tensile testing at ambient temperature. Brussels: European Committee for Standardization, 2005.

BS EN ISO 6507-1:2005. Metallic Materials-Vickers hardness test-Part 1: Test method. Brussels: European Committee for Standardization, 2005

Cheruvathur, S., Lass, E.A., Campbell, C.E., 2015. Additive Manufacturing of 17-4 PH Stainless Steel: Post-processing Heat Treatment to Achieve Uniform Reproducible Microstructure. Jom 68, 930-942.

Das, A., Tarafder, S., 2008. Geometry of dimples and its correlation with mechanical properties in austenitic stainless steel. Scr. Mater. 59, 1014-1017.

Das, C.R., Dey, H.C., Srinivasan, G., Albert, S.K., Bhaduri, A.K., Dasgupta, A., 2006. Weldability of $17-4 \mathrm{PH}$ stainless steel in overaged heat treated condition. Sci. Technol. Weld. Join. 11, 502-508.

Facchini, L., Vicente, N., Lonardelli, I., Magalini, E., Robotti, P., Alberto, M., 2010. Metastable austenite in 17-4 precipitation-hardening stainless steel produced by selective laser melting. Adv. Eng. Mater. 12, 184-188.

Frazier, W.E., 2014. Metal additive manufacturing: A review. J. Mater. Eng. Perform. 23, 1917-1928.

Hsiao, C.N., Chiou, C.S., Yang, J.R., 2002. Aging reactions in a 17-4 PH stainless steel 74, 134-142.

Järvinen, J.-P., Matilainen, V., Li, X., Piili, H., Salminen, A., Mäkelä, I., Nyrhilä, O., 2014. Characterization of Effect of Support Structures in Laser Additive Manufacturing of Stainless Steel. Phys. Procedia 56, 72-81.

LeBrun, T., Nakamoto, T., Horikawa, K., Kobayashi, H., 2015. Effect of retained austenite on subsequent thermal processing and resultant mechanical properties of selective laser melted 17-4 PH stainless steel. Mater. Des. 81, 4453.

Matilainen, V., Piili, H., Salminen, A., Syv??nen, T., Nyrhil??, O., 2014. Characterization of process efficiency improvement in laser additive manufacturing. Phys. Procedia 56, 317-326.

Rashid, R., Masood, S.H., Ruan, D., Palanisamy, S., Rahman Rashid, R.A., Brandt, M., 2017. Effect of scan strategy on density and metallurgical properties of 174PH parts printed by Selective Laser Melting (SLM). J. Mater. Process. Technol. 249, 502-511.

Wang, F., Williams, S., Colegrove, P., Antonysamy, A.A., 2013. Microstructure and mechanical properties of wire and arc additive manufactured Ti-6Al-4V. Metall. 
Mater. Trans. A Phys. Metall. Mater. Sci. 44, 968-977.

Williams, S.W., Martina, F., Addison, A.C., Ding, J., Pardal, G., Colegrove, P., 2015. Wire + arc additive manufacturing. Mater. Sci. Technol. 836, 1743284715Y.000.

Wong, K. V., Hernandez, A., 2012. A Review of Additive Manufacturing. ISRN Mech. Eng. 2012, 1-10.

Xiong, J., Lei, Y., Li, R., 2017. Finite element analysis and experimental validation of thermal behavior for thin-walled parts in GMAW-based additive manufacturing with various substrate preheating temperatures. Appl. Therm. Eng. 126, 43-52.

Yadollahi, A., Shamsaei, N., Thompson, M.S., Elwany, A., Bian, L., 2016. Effects of Building orientation and Heat Treatment on Fatigue Behavior of Selective Laser Melted 17-4 PH Stainless Steel. Submitt. to Int. J. Fatigue 1-18.

Yoo, W., Lee, J., Youn, K., Rhyim, Y., 2006. Study on the Microstructure and Mechanical Properties of 17-4 PH Stainless Steel depending on Heat Treatment and Aging Time. Solid State Phenom. 118, 15-20.

Zähr, J., Füssel, U., Hertel, M., Lohse, M., Sende, M., Schnick, M., 2012. Numerical and Experimental Studies of the Influence of Process Gases in Tig Welding Numerical and Experimental Studies of the Influence of Process Gases in Tig Welding. Weld. World 56, 85-92.

Ziewiec, A., Tasak, E., 2014. Microstructure of Welded Joints of X5CrNiCuNb16-4 (17-4 PH) Martensitic Stainless Steel After Heat Treatment. Arch. Metall. Mater. $59,965-970$. 


\section{Wire + Arc Additive Manufacture of 17-4}

PH stainless steel: Effect of different processing conditions on microstructure, hardness, and tensile strength

Caballero, Armando

Elsevier

Caballero A, Ding J, Ganguly S. (2019) Williams S. Wire + Arc Additive Manufacture of 17-4 PH stainless steel: Effect of different processing conditions on microstructure, hardness, and tensile strength. Journal of Materials Processing Technology, Volume 268, June 2019, pp. 54-62

https://doi.org/10.1016/j.jmatprotec.2019.01.007

Downloaded from Cranfield Library Services E-Repository 